\title{
RETÓRICAS DE LA PROXIMIDAD: LOS TWEETS PRESidenciales en la Argentina
}

\author{
María Elena Qués ${ }^{1}$
}

Resumen: Este artículo se propone analizar los recursos de construcción de la cercanía entre enunciador y destinatario empleados por la presidente Cristina Fernández de Kirchner en sus intervenciones en Twitter. Este soporte tiene rasgos que lo hacen especialmente interesante para observar las innovaciones discursivas asociadas al uso de la Web. En particular, Twitter favorece una puesta en escena del contacto uno a uno que produce un efecto de horizontalidad, que se superpone a las diferencias jerárquicas de los involucrados. Este rasgo del soporte se traduce en la utilización de recursos léxicos, retóricos y enunciativos (el tuteo, el humor, etc.) que refuerzan la construcción de un pacto de complicidad y cercanía con sus seguidores

\footnotetext{
Abstract: This article analyzes the communicational strategies that President Cristina Fernández de Kirchner deploys at Twitter in order to build an idea of closeness with her followers. Due to its features, Twitter has become an interesting space to see the innovations that Internet has brought to political discourses. By promoting a mise en scène of a peer-to-peer relationship, Twitter produces an idea of horizontality that overlaps the different status of those involved. This peculiarity of Twitter is related to lexical, rethorical and enunciative resources that reinforce the pact of complicity and closeness with her followers.

María Elena Qués es Licenciada en Letras por la Universidad de Buenos Aires y se ha especializado en análisis del discurso político. Ha publicado numerosos artículos sobre el tema y los libros La palabra acorralada y Politica, medios y discurso en Argentina, ambos en colaboración con Mariana Podetti y Cecilia Sagol. Actualmente es docente e investigadora de la Universidad de General Sarmiento y de la Universidad de Buenos Aires. E-mail: elenaques@gmail.com.
} 


\section{Introducción}

La irrupción de Internet -y, en particular, de las redes sociales- está comenzando a alterar entre nosotros el ecosistema de la comunicación política y reactualiza el ideal de una palabra transparente, una comunicación directa entre representantes y representados ajena a toda mediación. Tal politicidad "sin mediaciones" absorbe tanto los fantasmas de "un plus de verdad", derivado del "acceso directo" y la "visibilidad total", como las fantasías de la manipulación global e invisible (¿quién "está detrás" de Internet?). Ambas imágenes se alimentan, hasta cierto punto, del divorcio de la empiria que supone la comunicación virtual.

"Las tecnologías digitales -señala al respecto Lucrecia Escudero (2002)- encarnan todos los temas de una nueva y poderosa mitología moderna: la red que iguala, el anonimato, el intercontacto y el simulacro de la mente, la semiosis ilimitada de la navegación que reproduce la sinapsis del cerebro, el secreto y el complot". Esto es especialmente válido en el caso de la comunicación política. Las redes sociales permiten una puesta en escena más o menos ficcional del uno a uno, que se apoya en condiciones de recepción novedosas. A diferencia de la televisión, con Internet la recepción ya no es sólo privada, sino también individual, y a través de la telefonía celular, el consumo se disocia progresivamente de lo doméstico. Estamos ante un circuito comunicativo que se instala en las antípodas de la asamblea a la que los ciudadanos acuden en busca del sentido que los ratifica en su identidad y sus relaciones de pertenencia. La palabra de las redes sociales es una palabra nómade, de atribución incierta, que atrapa en su red al individuo en tránsito. ${ }^{2}$ Nuestro objetivo es mostrar

Hay una suerte de gradación en este proceso de transformación del circuito de la palabra política en la Argentina: de los actos callejeros 
las formas en que estos rasgos del medio se corresponden con cambios en el aparato de enunciación y los recursos retóricos que se ponen en juego. El corpus que tomamos para el análisis corresponde a las intervenciones de la presidente Cristina Fernández de Kirchner en Twitter durante el mes de octubre de 2010.

\subsection{Etapas y funciones en la relación entre política y nuevas tecnologías}

Una primera dificultad para analizar el impacto de la red sobre los discursos políticos es su permanente mutabilidad. La breve e intensa historia de estas prácticas en la Argentina se podría segmentar en tres etapas en las que la intersección de política y nuevas tecnologías ha asumido formas diversas que, a su vez, corresponden a diferentes tipos de sujetos:

Una primera etapa "institucional" en la que los partidos abrieron -con mayor o menor fortuna y continuidad- sitios web destinados a mantener actualizados los canales de comunicación con sus simpatizantes, dirigentes y afiliados (Qués, 2010). Estos sitios funcionan fundamentalmente como un instrumento para agilizar la comunicación interna y la relación con la prensa (a través de la publicación de gacetillas y documentos institucionales). En sus orígenes, los sitios web partidarios tuvieron cierta connotación de transparencia asociada a

multitudinarios, que caracterizaron la campaña electoral de 1983, a las caravanas de fines de los años 1980, en las que los políticos recorrían sus distritos en busca del contacto con los votantes. En los años 1990, tuvieron su apogeo los diversos formatos de la telepolítica, y con ellos, la recepción en el ámbito privado, doméstico. Con las redes y la telefonía celular se configura un nuevo escenario, de recepción individual y ubicua. Ninguno de estos formatos cancela los anteriores, claro está, pero el surgimiento de cada uno de ellos redefine el funcionamiento del sistema e irradia su estilo sobre los otros subgéneros. 
un discurso de mayor alcance en torno a la relación entre Internet y el acceso a la información. Una marca de esta tendencia es que los partidos publicaban, por ejemplo, una rendición de cuentas de los gastos de campaña. El nuevo medio nacía ligado a un nuevo verosímil (o a un viejo verosímil reactualizado), potenciado por otros discursos que instalaban el tópico de Internet como herramienta de la transparencia política e incluso como un eventual antídoto contra la secrecidad y la corrupción, tópicos recurrentes del discurso político y periodístico finisecular. Hoy podríamos decir que la promesa que se tematiza ya no es tanto la transparencia como la participación, ligada a otros canales y formatos (FB, Twitter, cadenas de mails, blogs).

Una segunda etapa exploratoria de los formatos 2.0 -disparada por el "efecto Obama" - se centró en la difusión de la propaganda de uso electoral. Una incorporación un tanto superficial o mecánica de las herramientas usadas en la campaña norteamericana, que se tradujo en la fundación de espacios ligados a candidatos y a fórmulas, más que a partidos. La superficialidad de la apuesta se verifica en el hecho de que muchas veces los sitios fueron abandonados después de la elección.

Se trataba de instrumentos que la doxa electoral dictaminó como necesarios para completar el "cotillón de campaña" sin que su uso se hiciera carne en los usuarios, ni como productores, ni como receptores. Por cierto que el escaso impacto de estas primeras exploraciones está asociado también al carácter incipiente de la penetración de Internet en aquel momento. En estos casos, la red tendió a funcionar como metamedio, es decir, un soporte innovador para fortalecer la difusión de materiales diseñados para otros medios (columnas de opinión, spots, afiches). 
El tercer tiempo -el presente- se caracteriza por el impacto creciente que las redes sociales y el microblogging $^{3}$ han tenido de manera notable en los últimos años, a partir de dos fenómenos: (a) la intervención de figuras políticas del gobierno nacional en polémicas coyunturales a través de estos soportes y (b) la hostilidad existente entre el gobierno nacional y una parte importante de la prensa tradicional que abonó la búsqueda de canales alternativos. ${ }^{4}$

La evolución de los usos de Internet, como vemos, ha afianzado las formas discursivas más afines a enunciadores individuales, lo cual establece una fuerte sintonía entre los atributos del medio, una cultura política marcada por el personalismo y un sistema de partidos profundamente resquebrajado.

3 El crecimiento de Twitter, por ejemplo, ha sido clasificado de explosivo pese a no tratarse de un fenómenos masivo ( 100.000 cuentas contra 5.000 .000 de Facebook a nivel nacional, en 2010. Fuente: Adrián González Aón, entrevista personal). Sin embargo, como se trata de un canal en el que intervienen mayoritariamente líderes de opinión (personalidades públicas, artistas, músicos, modelos, políticos y periodistas), el impacto público es mayor. Por otra parte, la dinámica propia del Twitter se distingue de FB en que no es una red social en sentido estricto, sino una plataforma de microblogging. Es decir: 1) no supone vínculos de afinidad entre seguidores y seguidos (a diferencia de $\mathrm{FB}$, en el que la incorporación es por vínculos de amistad o expresión de gusto o disgusto); 2) frecuentemente el usuario de TW actúa como una suerte de voyeur, es decir, que tiene su cuenta sólo para poder seguir y "leer" los dichos de su artista favorito o de un dirigente político, pero que no emite nada; 3 ) predomina cierto perfil de sujetos "autorizados" según las diversas lógicas propias de su rama de actividad.

4 En el año 2008, se produjo un fuerte enfrentamiento entre el Gobierno Nacional y sectores agropecuarios que resistían la implantación de cambios en las retenciones a las exportaciones de soja. El apoyo a dichos sectores por parte de grandes diarios nacionales derivó en una creciente hostilidad entre el oficialismo y la principal empresa de multimedios, más tarde potenciada por el debate en torno a la nueva ley de medios audiovisuales y al manejo de la empresa Papel Prensa. En ese contexto, el impacto de las intervenciones de los funcionarios en Twitter se vio favorecido por la recuperación de esas polémicas en los medios tradicionales, en un clima de mutuas lecturas hostiles. 


\subsection{Soportes, formatos, géneros}

Otra dificultad a tener en cuenta cuando se trata de analizar discursos que circulan en la Web es el desafío de fijar una terminología para referirnos a la variedad de géneros que nacen al calor de los nuevos usos discursivos.

Al respecto, es interesante recuperar la distinción que hace Eliseo Verón (2004) para pensar los vínculos entre los discursos y sus soportes gráficos. El autor discrimina los que él llama "géneros L" (entrevistas, alocuciones, debates), caracterizados "por cierta disposición de materia lingüística", y los "géneros P", categoría que propone provisoriamente para designar y clasificar productos (revista femenina, semanario de información general). "Sujetos a competencia (y atravesados por los 'géneros L'), los géneros $\mathrm{P}$ configuran un contrato de lectura, sobre cuya base construirán un lectorado". Los géneros L, señala Verón, "están sobredeterminados por el tipo de discurso y por el género $P$ en cuestión". Desde este punto de vista, los diversos géneros de la Web admitirían ser considerados "géneros P". Al difundirse en este entorno, el discurso político suma un nuevo tipo de determinaciones diferentes de aquellas que han moldeado su tradición como "género L" y de las que han derivado de la circulación en la prensa y la televisión.

\subsection{Me lo contó un pajarito: notas sobre Twitter}

Microeditoriales, fragmentos de polémicas, comentarios de coyuntura, improperios o intercambios crípticos entre pares, la apuesta a la brevedad de Twitter se solapa con las tradiciones discursivas de la política, dando lugar a híbridos que siguen una lógica propia. Siempre ávida de expansión, la palabra política echa mano de los recursos disponibles para ampliar los 140 caracteres al infinito, incluyendo links a otros textos, videos, artículos, 
etc., o remitiendo a otros espacios ligados al enunciador (Facebook, páginas personales, blogs, etc.).

Podríamos decir que en Twitter los indicios de cercanía están hipertrofiados. La atmósfera de Twitter se presta a la informalidad, al comentario casual, cotidiano, que favorecen la postulación de vínculos de familiaridad e identificación entre enunciador y destinatario. Por eso, diga lo que diga el tweet, es la función del contacto ${ }^{5}$ la que, desde nuestro punto de vista, otorga el mayor atractivo a esta modalidad. Se trata de mensajes cuya eficacia reside en que su sola enunciación es un indicio del vínculo que liga al enunciador y el destinatario. ${ }^{6}$

Como era de esperar, también surgen tensiones entre las nuevas tendencias y los ideales de comunicación obsoletos -pero que aún operan en el imaginario-, en particular cuando de trata de figuras jerarquizadas del ámbito público. Por ejemplo, la cobertura periodística del ingreso de CFK a Twitter estuvo mechada por comentarios que implícita o explícitamente sugerían una contradicción entre la majestad del cargo y la informalidad del soporte. ${ }^{7}$ Es interesante

La definición más tradicional de la función del contacto es la formulada por Roman Jakobson (1960): "Hay mensajes que sirven sobre todo para establecer, prolongar o interrumpir la comunicación, para cerciorarse de que el canal funciona ('Oye, ¿me escuchas?'), para llamar la atención del interlocutor o confirmar si su atención se mantiene". Eliseo Verón (1985), por su parte, señala que todo hecho comunicativo "está rodeado, atravesado y sostenido por una multitud de elementos significantes verbales y no verbales destinados a establecer, controlar, calibrar o reforzar el vínculo entre los interlocutores".

6 Evidentemente, como ocurre en todo discurso, la postulación del vínculo por parte del enunciador no implica su aceptación efectiva por parte de los lectores.

7 Por ejemplo, Lucrecia Bullrich escribía en La Nación el 6 de septiembre de 2010: "La decisión presidencial de incorporarse al mundo de los 140 caracteres genera interrogantes. ¿Cómo encaja el Twitter en el aparato comunicacional de Cristina Kirchner? ¿Qué beneficios puede reportarle el uso de la red social? ¿Corre algún riesgo?”. Disponible en línea: http:// 
notar la movilidad presidencial entre la recuperación de formatos más estrictamente clásicos de comunicación gubernamental -como la cadena nacional, que había caído en desuso ${ }^{8}$ y los formatos más innovadores (Twitter, Facebook, YouTube) que a la vez recuperan, potencian y archivan las emisiones en formatos tradicionales.

\section{Los tweets de Cristina}

\subsection{El orden de lo indicial}

Como hemos señalado, la marca diferencial de Twitter está ligada a la inmediatez del contacto, que ofrece condiciones novedosas para una participación imaginaria de los seguidores en la esfera de lo público. Este rasgo tiene su correlato discursivo en una insistente explicitación de la situación de enunciación: de algún modo, más allá del tema al que se refieran, lo que los tweets comunican es: "Yo estoy acá y te estoy hablando a vos".

Como afirma Beatriz Sarlo (2011), "Twitter hace correr en paralelo dos sistemas jerárquicos: uno fundado en lo que se ha ganado allí, en esa plataforma; el otro fundado en la mezcla de capital que se trae desde afuera del mundo web con la habilidad innata o adquirida para manejarse adentro".

www.lanacion.com.ar/1301892-cristina-kirchner-en-twitter-beneficioslimites-y-riesgos.

$8 \quad$ Hasta fines de la década de 1980, las apariciones televisivas del Presidente de la Nación se daban de modo casi exclusivo a través de la cadena nacional de radio y televisión. Las emisiones en cadena tenían un formato rígidamente pautado e implicaban la suspensión de la programación de todos los canales y radios, que transmitían el mensaje en simultáneo. A partir de la presidencia de Carlos Menem, la cadena nacional prácticamente dejó de utilizarse hasta el año 2008, cuando Cristina F. de Kirchner la retomó, con características formales más flexibles. 
Por eso, el impacto de estos recursos de acercamiento es más intenso cuanto mayor sea la distancia jerárquica entre enunciador y destinatario. El vínculo de cercanía se ve favorecido por los rasgos del soporte, pero no lo garantizan por sí solos. ${ }^{9}$ Como veremos al analizar los ejemplos, es necesario que la enunciadora ponga en juego una serie de mecanismos enunciativos, léxicos y argumentativos para que esa promesa se haga efectiva. Las formas tradicionales de la retórica política se superponen así con recursos del lenguaje familiar cotidiano.

Veamos un ejemplo: ${ }^{10}$

CFKArgentina. Acabo de llegar de la planta de Pirelli en Merlo, provincia de Buenos Aires. El CEO Global anunció una inversión por us\$ 100 millones.

CFKArgentina. Estaba al tanto de una inversión de us\$80 millones pero en las últimas horas decidieron agregar us\$ 20 millones más. ¿Qué tul?

20 de octubre de 2010

En este caso, y en los que se verán más adelante, las marcas verbales, espacio-temporales y de persona permiten reconstruir la situación de enunciación. Podría objetarse que toda escritura debe ofrecer indicios que permitan al lector reponer información sobre la situación de enunciación. Lo inédito es que en el contexto de las redes accedemos a la novedad al mismo tiempo que la Presidente de la Nación, que nos lo comunica personalmente, en un tono coloquial que connota un borramiento ilusorio de las jerarquías. Subraya Beatriz Sarlo (op. cit.) que "Twitter es un horno de fusión entre estos cruces léxicos y se convierte

9 De hecho, luego de la muerte de Néstor Kirchner, los tweets presidenciales adquirieron un tono impersonal, limitados a cuestiones de agenda y seguramente emitidos por el equipo de prensa.

10 Para facilitar la lectura, presentamos las secuencias de tweets en orden cronológico. Como es sabido, en pantalla encontramos las intervenciones ordenadas a partir del envío más reciente. 
en un instrumento tanto más flexible cuantas más variantes dialectales se manejen. Twitter es Internet pero se localiza instantáneamente en la lengua".

La enunciadora nos invita a compartir la sorpresa y a reponer la argumentación que se postula entre líneas: las buenas nuevas superan las expectativas del sentido común. El carácter inesperado que se atribuye a la noticia y la inmediatez temporal operan como un resguardo del efecto de propaganda y del halo de sospecha a ella asociado. Una acción de propaganda supone un tiempo de reflexión, preparación y construcción, y la participación de especialistas, etc. En tal sentido, las diferentes formas de presentar los dichos como espontáneos en su inmediatez fortalecen la verosimilitud del enunciado.

\subsection{Complicidad y lazos de pertenencia}

Otra función de los tweets es la de reforzar los lazos de pertenencia a un colectivo común a través de guiños o sobreentendidos que condensan argumentos y polémicas difundidos a través de otros soportes. El uso del tuteo como marca de intimidad se ve reforzado por un tipo de interpelación que postula una historia previa del vínculo entre la enunciadora y sus destinatarios ("ya sabés"; "aunque no lo creas"):

CFKArgentina. Me enteré por los medios que la Secretaría de Derechos Humanos, presentó nuevas pruebas en el Caso Papel Prensa.

CFKArgentina. Le he pedido a Duhalde, ya sabés, Eduardo Luis (el bueno) que me acercara el escrito.

CFKArgentina. Un verdadero conjunto de políticas públicas de Estado. Democratización a full. Sorry, Magnetto, el futuro está llegando.

19 de octubre de $2010^{11}$

11 Esta secuencia se encuadra en el marco de la mencionada disputa entre el Gobierno Nacional y las empresas responsables de los dos diarios 
El juego doble de igualación ("me enteré por los medios") y distanciamiento jerárquico ("le pedí a...") es paralelo al desdoblamiento que se opera en la destinación (vos / Magneto). Desde el vértice de la escala jerárquica, la enunciadora puede interpelar a la vez al simpatizante, al funcionario y al empresario opositor. Para el destinatario, cuyas creencias se presuponen compartidas, el guiño de simpatía y el tono risueño. Para el adversario, la ironía y lo que Borges (1933) llamaba "el falso aparato de la piedad". Esta última interpelación es una puesta en escena, un espectáculo ofrecido para regocijo del simpatizante. En síntesis, la función del enunciado no es informar sobre las novedades del caso Papel Prensa -que no se explicitan- o introducir nuevos argumentos, sino ratificar las demarcaciones del campo político y anclar al destinatario en el sector afín.

\subsection{Anecdotario y cotidianeidad}

El tercer recurso al que nos referiremos consiste en insertar secuencias anecdóticas, banales, cuya función se asocia a lo que la retórica clásica llamaba capatio benevolentiae, y que, en términos más contemporáneos, podríamos calificar de estrategias de acercamiento emocional.

Por otra parte, la inclusión de detalles nimios refuerza la verosimilitud del conjunto. Como señalaba Roland Barthes (1968) al analizar la novela realista, "se considera

nacionales de mayor tirada, copropietarias asimismo de la principal empresa de producción de papel. Reseñar la complejísima historia de Papel Prensa es algo que excede los objetivos de este artículo. Para una síntesis de la perspectiva gubernamental sobre el tema, ver, disponible en línea: http://www.argentina.ar/_es/pais/C4475-papel-prensa-la-verdad. php. En cuanto a los nombres mencionados, se refieren a Eduardo Luis Duhalde, Secretario de Derechos Humanos de la Presidencia de la Nación, y a Héctor Magneto, Director Ejecutivo del diario Clarín, blanco preferencial de las arengas oficialistas. Entre líneas, se alude al ex presidente Eduardo Duhalde, referente de un sector del peronismo enfrentado con el gobierno. 
'lo real' como autosuficiente, que es lo bastante fuerte como para desmentir toda idea de función, que su enunciación no tiene ninguna necesidad de ser integrado a una estructura y que el haber-estado-allí es un principio suficiente para la toma de la palabra". La gratuidad de la información presentada la rodea de un aura de independiencia de una finalidad ulterior y sólo se explica por su carácter real.

CFKArgentina. CFK, discurso con saludo alemán en grado de tentativa... Mejor sigo con lo mío.

CFKArgentina. El chofer se llama Jörg Geffner y le dicen Yol, más alemán q chucrut. Contó q viene d la RDA y no deja de señalar los restos del muro.

CFKArgentina. Siento que también han quedado huellas en las almas. Aufwiedersehen Berlín.

8 de octubre de 2010

La utilización de este recurso es particularmente frecuente en los tweets emitidos durante la estadía de Cristina Fernández de Kirchner en Berlín. La distancia jerárquica y geográfica se disuelve mediante el desparpajo de la comparación y la puesta en escena de la mirada turística. Se despliega un efecto igualador de las dificultades idiomáticas y las distancias culturales, que facilita los lazos de complicidad al aludir, por contraste, a una identidad cultural y lingüística compartida con los seguidores. Los toques cool, dados por la economía de caracteres, los giros coloquiales, la inclusión de términos en alemán como indicios del contexto de enunciación y la segmentación del relato favorecen asimismo el efecto de cercanía.

Por otra parte, la autoironía remite -en un juego que discrimina saberes pertinentes y no pertinentes-ignorancia de la lengua alemana y manejo de jerga jurídica. De esta manera, se producen simultáneamente dos movimientos opuestos: la borradura y la afirmación de la jeraquía presidencial. 


\subsection{Anecdotario y modelo}

Una variante del relato anecdótico presenta situaciones que se plantean como indicios a partir de los cuales es posible reconstruir la tópica característica del discurso oficialista ya instalada por otros medios. Esta estrategia le permite a CFK construir un perfil discursivo en el que es a la vez testigo y protagonista, y le da a la propaganda de la gestión una vivacidad de la que habitualmente carece la comunicación gubernamental clásica. El uso de lo que en literatura se denomina discurso indirecto libre le permite salpicar el relato con fragmentos de diálogos, romper la isotopía, incluir comentarios ligeramente jocosos e interpelaciones directas al lector, que anticipan sus reacciones y orientan la interpretación de los hechos narrados.

CFKArgentina. Lo mejor fue a la salida d hotel $p /$ la cena. Tres jóvenes estaban esperando ¿ Son argentinos? "Sil" ¿Están estudiando? Muy convencional lo mío.

CFKArgentina. "No. Somos operarios de Volkswagen de la Planta de Pacheco que vinimos a capacitar obreros alemanes sobre la camioneta Amarok".

CFKArgentina. Me quedé muda, aunque no lo creas. "Todo gracias a Ud., Sra. Presidenta”, completaron. Reaccioné, NO. Es gracias a Uds. Mucho orgullo y fotos.

9 de octubre de 2010

Nuevamente, la seudoautocrítica -"muy convencional lo mío" - traza un umbral de modestia personal que destaca, por contraste, la moraleja implícita. Como en los antiguos folletines, que interrumpían la entrega en un momento clave de la intriga, la secuencia de los tweets produce cierto suspense, la incógnita planteada en el primero se revela en el segundo. Así como el devenir del relato invierte la circulación del saber (estudiar / capacitar), se produce un movimiento similar en cierre, con la reciprocidad de agradecimientos entre los operarios y CFK. 


\subsection{Intimismo, humor y modelo}

En algunas oportunidades, los tweets recuperan una atmósfera más intimista. También aquí encontramos el recurso al suspense, escenificado a través de la supuesta alarma del lector, producida por la opacidad del lenguaje científico.

CFKArgentina. Apostillas ${ }^{12}$ II. "Onzelumia Orquidácea CFK". Uyyy... ¿qué le pasó?

CFKArgentina. Nada, escuchá. El viernes recibí en Olivos una maceta con una planta de Orquídea. Colores y forma de las flores indescriptibles.

CFKArgentina. Bellísima. Viene con nota y certificado de la especie.

CFKArgentina. Orquídea Nota: Productor de orquídeas de empresa creada en 2003. Más de 50.000 orquídeas por año, cuarenta variedades, híbridos y ¡clones!

16 de octubre de 2010

La secuencia va del agasajo personal a la interpretación en clave de indicio del salto tecnológico y productivo, que se impone como moraleja. El lugar de enunciación de CFK vira del ámbito privado y de cierta reafirmación de la femineidad a la figura pública que encuadra el episodio en el tiempo de las sucesivas gestiones de Néstor y Cristina Kirchner. Del juego de equívocos generados por el desconocimiento de la terminología científica a la exhibición del saber. Como en los casos anteriores, hay una suerte de doble faz de la enunciadora: la que encarna el sentido común del ciudadano medio observa con cierta ingenuidad y sorpresa las manifestaciones más cotidianas de los cambios. La figura institucional encuadra y orienta la interpretación de esas señales en apariencia autónomas como manifestaciones del "modelo". En cierto modo,

12 Según la definición de la RAE, la apostilla es una "acotación que comenta, interpreta o completa un texto". 
esa doble construcción reproduce el slogan acuñado por Néstor Kirchner para definir el rol presidencial como una combinación de "la persona común" y la "responsabilidad extraordinaria”.

\subsection{Argumentación clásica}

Otras secuencias de tweets se encuadran, por el contrario, dentro de lo que podríamos llamar argumentación clásica. Por lo general, corresponden a secuencias en las que predomina el carácter polémico.

CFKArgentina. Otra medida cautelar, ahora para Shell. Para que pueda aumentar a gusto el precio de la nafta, que VOS pagás.

CFKArgentina. ¿Dictan medidas cautelares a los evasores que te roban hospitales, escuelas, caminos y casas?

CFKArgentina. ¿Dictan medidas cautelares a las multinacionales que descuentan a productores argentinos hasta el aire y después no pagan impuestos?

7 de octubre de 2010

En estos casos, que segmentan en 140 caracteres lo que podría ser un fragmento de un discurso de tribuna, se recupera el registro pedagógico -característico del discurso de la Presidente en otros contextos- y reaparece la distancia jerárquica frente al destinatario. Sin embargo, mantiene recursos como la hipérbole, la inclusión del destinatario individualizado a través del tuteo, la presuposición del continuum, que se supone ya conocido y que da sentido al caso particular. En este caso, las marcas de tal presuposición están dadas por los indicadores de reiteración ("otra", "ahora") y por la serie de preguntas retóricas. El refuerzo del vínculo corre por carriles más tradicionales: se refuerza la alianza yotú vs. "ellos" (los que evaden / roban, pero también los que dictan / no dictan medidas cautelares, presentados como equivalentes). Desaparecen la complicidad y la simetría 
en el vínculo con el destinatario, que se transforma en una alianza -necesariamente asimétrica- entre la víctima y su defensora. ${ }^{13}$ Recupera así un tópico ya clásico del kirchnerismo, una suerte de oxímoron que podríamos denominar "la rebeldía desde el poder". El sesgo contradictorio de tal formulación se compatibiliza denunciando un poder espurio en otro ámbito oscuro y extrainstitucional. En este caso, se postula una alianza non sancta entre un sector de la Justicia y una empresa petrolera.

Similar es la estrategia utilizada en los días que siguieron al asesinato del militante izquierdista Mariano Ferreyra por parte de una patota vinculada a la conducción sindical. La argumentación, destinada a negar eventuales nexos entre los responsables del crimen con miembros del gabinete nacional, se mantiene dentro de carriles más tradicionales. La secuencia desplaza el tema hacia el enfrentamiento entre el Gobierno y la prensa opositora; los seguidores pueden reponer sin mayores dificultades las lagunas argumentativas, forzadas por el corsé de los 140 caracteres:

CFKArgentina. Clarín y La Nación publicaron fotos del presunto asesino de Mariano (no olvides que además de Presidenta soy abogada) con Boudou y Sileoni. ${ }^{14}$

13 Las secuencias polémicas tienen, obviamente, mayor repercusión en los medios tradicionales. La intervención que tomamos como ejemplo fue interpretada por la prensa opositora como un episodio más de la escalada de conflictos entre el Poder Ejecutivo Nacional y la Justicia "En medio de una fuerte disputa con la Corte Suprema por la Ley de Medios y la restitución de un procurador en Santa Cruz, la presidenta Cristina Kirchner volvió a atacar hoy a la Justicia, a la que acusó de apañar a 'los evasores y los que aumentan los precios.' Pero la Presidenta fue más allá y señaló que el país está 'en manos de las corporaciones.' En ese sentido, utilizó una frase sintética para definir la actual conflictiva relación entre el Poder Ejecutivo y el Judicial: 'La Argentina al revés"'. (La Nación, 7 de octubre de 2010).

14 Se refiere a Amado Boudou, entonces Ministro de Economía y actual Vicepresidente, y a Alberto Sileoni, Ministro de Educación. 
CFKArgentina. Las fotos son de ocasión, tomadas en peña abierta al público q Boudou hace todos los miércoles. Pública, notoria y visitada por periodistas.

CFKArgentina. ¿Te imaginarás la cantidad de fotos que esta Presidenta se habrá sacado, con millones de personas desconocidas, durante más de 20 años?

23 de octubre de 2010

\section{Recapitulando}

Las redes sociales facilitan la proliferación de las retóricas de la cercanía, lo cual implica el surgimiento de formas híbridas que articulan las tradiciones del discurso político con las formas propias de los géneros 2.0. Por otra parte, en estos nuevos espacios resultan afines a formas político-discursivas ligadas a enunciadores individuales y al refuerzo de los vínculos emocionales por encima de los desarrollos argumentativos, que sólo aparecen evocados a través de indicios, datos, anécdotas.

En el corpus analizado, los principales recursos de construcción de la cercanía son, en el orden de la enunciación, la insistencia en la inmediatez -el aquí y ahora-, la interpelación directa e informal a un destinatario individual, y los giros de humor y autoironía que refuerzan el vínculo de complicidad.

En otro plano, en los textos abunda el uso de giros informales, el juego polifónico, la puesta en escena intimista, a través de un anecdotario cuya banalidad sugiere una atmósfera lúdica.

Estos recursos le permiten a la enunciadora zigzaguear entre una faceta de sentido común, que construye un vínculo inter pares, y la faceta político-institucional, que encuadra el sentido de los dichos.

En cuanto a la argumentación, el destinatario presupuesto es un sujeto ya convencido al que le bastan indicios 
para reconstruir una cadena argumentativa conocida y aceptada. Los dispositivos argumentativos más tradicionales se reservan para los momentos polémicos, en los que le resulta necesario reducir los márgenes de ambigüedad.

Como se ha señalado, este estilo de comunicación se interrumpió a partir de la muerte de Néstor Kirchner. Desde entonces, los tweets se limitan a informar sobre la agenda presidencial en un tono más bien neutro, o a reproducir -segmentados en 140 caracteres- fragmentos de discursos presidenciales producidos en otros ámbitos.

\section{Bibliografía}

Barthes, Roland(1968), "El efecto delo real", Comunicaciones. Lo verosímil, Buenos Aires, Editorial Tiempo Contemporáneo.

Borges, Jorge Luis (1933) "El arte de injuriar", Obras completas, Buenos Aires, Emecé.

Escudero Chauvel, Lucrecia (2002), "Editorial”, Signis $n^{\circ} 5$ Corpus Digitalis- Semióticas del mundo digital, Barcelona, Gedisa, diciembre de 2003. ISSN 1519 4223. Disponible en línea: http://www.designisfels.net/designis5.htm.

Jakobson, Roman (1960), "Lingüística y poética”, Ensayos de lingüística general, Barcelona, Planeta.

Qués, María Elena (2010), "Enunciación política y nuevas tecnologías: análisis de las páginas de inicio de la UCR y el PJ", ponencia presentada en el XII Congreso de la Sociedad Argentina de Lingüística Mendoza, abril de 2010.

Sarlo, Beatriz (2011), La audacia y el cálculo. Kirchner 2003-2010, Buenos Aires, Sudamericana.

Verón, Eliseo (2004), "Prensa gráfica y teoría de los discursos sociales: producción, recepción, regulación”, Fragmentos de un tejido, Barcelona, Gedisa. 